\title{
Collaboration through Cartoons: Drawing Cartoons to Assist Collaborative Ethnography with Young Children
}

\author{
CHRISTINA FASHANU \\ The University of Sheffield, UK
}

\begin{abstract}
Representing participants' perspectives faithfully is a fundamental principle for collaborative ethnography (Lassiter 2005). Collaboration is difficult to achieve, however, when the participants are young children who do not share a language with the researcher. This article presents an innovative methodological approach that was employed during a twelve month, ESRC funded research project that aimed to explore the communicative practices of young children in a super-diverse, early years educational environment. In addition to writing field notes, the researcher sketched cartoon strips of the events being observed and shared these with the children. The paper describes how the cartoons facilitated a more collaborative approach to ethnographic research as the children became engaged in their creation and interpretation. The findings suggest that cartoons provide an accessible medium that opens up spaces for developing dialogue around the research process. This has important implications for any research that endeavours to listen to the participants' perspectives, but particularly where the participants are young children or in cases where the researcher does not speak the languages of the participants fluently.
\end{abstract}

\section{Introduction}

This paper describes how cartoons were used to address methodological challenges encountered during a particular ethnographic study working with four and five-year-old participants from diverse backgrounds. While conducting the research I became increasingly aware of the multi-faceted power imbalance between: adult-child, researcher-participant, English speaker- speakers of English as an additional language. While early years' researchers are becoming ever more conscious of children as active social agents, and accordingly, the necessity to include children's opinions in the research (Brooker 2011), questions regarding how to do this remain. The method described in this paper is readily available to all researchers as it does not require special expertise or resources and it has the potential to facilitate dialogue between the researcher and children, or indeed any participants who may find it difficult to access the researcher's notes. Though debates around wider participatory research exist, the focus of this paper will be a specific methodology that emphasises the need to include participants throughout the research: collaborative ethnography (Lassiter 2005).

\section{Aim}

With the above introduction in mind, the aim of this paper is to demonstrate how I used cartoons in a specific research project and to explain how this method relates to the four domains of collaborative ethnography, as outlined by Lassiter (2005). 
To achieve this aim, the next section will discuss the context of the research, after which the concept of collaborative ethnography will be summarised. I will then look in detail at four challenges for collaborative ethnography and explore how I used cartoons to address each challenge.

\section{The fieldwork}

The method discussed here developed in response to methodological challenges faced during a particular research project. The research is funded by the Economic and Social Research Council and aims to explore the communication practices of children in a super-diverse, early years environment. The participants are super diverse in that they come from countries across the globe, they speak English to varying degrees, they came to the school through multiple channels of migration, they had a variety of educational experiences before attending this school and many more variables besides (Vertovec 2007).

The principle method of data collection is ethnography as it is widely used in educational research (Bloome and Green 1997). Ethnography is also particularly appropriate for exploring interactions as they occur in 'natural' (as opposed to laboratory) conditions (Hymes 1974). My aim was not only to observe the children's interactions, but also to provide maximum opportunity for the children to be active participants in the research (Kirk 2007). Conducting research with young participants presents numerous challenges, particularly in terms of power relations between the researcher and the children (Christensen 2004). Issues of representation are common as the researcher endeavours to listen to children's voices in order to understand and portray their perspectives accurately (Tangen 2008). I wanted address the unavoidable power imbalance that exists between myself as an adult and the children, and myself as a researcher and the participants (Lahman 2008); (Graham et al. 2015). With these aims in mind, I adopted a collaborative ethnographic approach.

When using the term 'collaborative ethnography' I am specifically referring to the methodology developed by Lassiter and Campbell (Lassiter et al. 2004). While all ethnographic studies are, to a degree, collaborative, the collaborative ethnography model emphasises the deliberate process of collaboration with the community (Lassiter 2005). In this respect, issues concerning who has the right to be represented by whom and for what purpose date back to colonial anthropology, and collaboration as a response can be traced back to the renowned anthropologist Bronislaw Malinowski, who encouraged researchers to 'step off the veranda' (Malinowski 1922). Since then, ethnography has developed an increased consciousness regarding the politics and ethics of representation. 
Current collaborative ethnography is designed to overcome four key concerns: 1) ethics and moral responsibility, 2) ethnographic honesty, 3) accessible writing, and 4) collaborative reading, writing and co-interpretation (Lassiter 2012, pp. 77-154). Whilst these domains of concern are potentially difficult to navigate in any ethnographic research project, in my investigation the difficulties were intensified by the nature of my participants - namely young children from diverse cultural backgrounds with varying competencies in the English language.

\section{Collaboration through cartoons in theory}

The idea of using cartoons with the children evolved from the overall collaborative ethnographical research approach that I had decided to adopt. The aim was to engage the participants (i.e. the children in the class) in dialogue around the ethnographic texts being produced in order to gain deeper insights into their perspectives. In adopting this approach, I recognise that I was, in no way, absolving myself of responsibility for the decisions I made, rather, by providing a mutually accessible platform for communication, I was able to address collaborative ethnography's four domains of concern (as indicated above), and thereby help to balance the unavoidable unequal power relation between myself and the children (Flewitt 2005). Each of these four key domains will now be considered.

The method discussed here developed in response to methodological challenges faced during a particular research project. The research is funded by the Economic and Social Research Council and aims to explore the communication.

\section{- Ethics and moral responsibility}

While according to Lassiter, "Collaborative ethnography is first and foremost an ethical and moral enterprise' (2005, p. 79), there are many aspects of collaborative ethnographic research which pose particularly difficult ethical dilemmas. Firstly, the agenda of the research project must, of itself, be ethical. In this respect, my research project is designed to illuminate the communication practices of four to five-year-old children in a super-diverse environment. The participants are vulnerable, firstly because of their young age. I contend that childhood holds value in itself (Qvortrup 2004) and that children are active social agents, not just incomplete adults (Uprichard 2008). The participants are of minority ethnicities and most of them speak English as an additional language. Thus, the participants are subject to intersecting marginalities' (Lahman 2008, p.282), making them a particularly vulnerable and under-represented community due to their young age, their minority ethnicities and their varying levels of English competency. Key to the design of the research project was the goal of listening to the perspectives of the children (Christensen 2004; Brooker 2011). 
In this respect, the research is aligned with the United Nations Convention on the Rights of the Child which encourages adults to listen to and involve children when making decisions that affect them (UNICEF 1989). Practitioners and researchers engaged in the early years' education are increasingly adopting the view that children are active social agents and stakeholders with valid opinions and perspectives (Qvortrup 2004; Brooker 2011). As such, children have the right to speak, and researchers have the responsibility to take what children have to say seriously (Brooker 2011). Thus, the use of cartoons is a way of establishing dialogue between the researcher and the children through which it became easier to listen to the latter's perspectives on all aspects of the research.

In addition to the child-adult relationship, an inevitable power imbalance exists between the researcher and the participants. In the case of Lassiter's work, an ethnographic study had been conducted in Muncie, or 'Middletown' as the researchers called it that almost entirely excluded the African American population of the town. The researchers had the power to choose what to include and exclude from their report, thus it was the task of Lassiter, Campbell and their team to address this power imbalance by conducting collaborative research, involving the participants at all stages of the research project (Lassiter et al. 2004). In the same way I, the researcher, had the power to include or exclude information thus by employing a collaborative ethnographic approach I was able to take steps towards addressing challenges presented by the research-participant relationship.

Despite the inherent asymmetry, there were times when a child took the pencil and paper from me and drew on my notes. By doing this the 'power', embodied by my pencil and paper, was not fixed, but fluid and could shift between us (Christensen 2004). This led me to ask the children to draw a picture of themselves, and from that point on I used their own self-portraits as the characters in the cartoons. In this way, I established a channel through which the children could be co-creators of the ethnographic texts I produced.

More broadly, research with young participants is riddled with ongoing debates around consent (Gallagher et al. 2010). With this in mind, and in addition to gaining formal consent from the children's parents or carers, I chose to ask the children explicitly for their consent, as recommended by the British Education Research Association guidelines (British Educational Research Association 2011). Whilst obtaining consent prior to the start of a research project is typically referred to as 'informed consent', it is doubtful whether the consent was, in reality, fully 'informed'. This reflected the exploratory nature of the project and, hence, the absence of a clearly defined direction of travel as well as to the participants' young age and their associated difficulties in fully understanding the research project and its consequences. As a result, I used the more appropriate term 'provisional 
consent' (Flewitt 2005, p.4) - in other words that the participants' consent was provisional on the basis that the research would remain within agreed boundaries, and the tenets of confidentiality and anonymity would be upheld throughout. This provisional consent was achieved by providing the children with a cartoon strip that summarised the research process, and where possible by using translators armed with the use of the cartoon as a visual aid to explain the project and its consequences to the children in their own language.

Initial consent is necessary when conducting research, but not sufficient (Graham et al. 2015). It was vital that I remained sensitive and responsive to the children's reactions to my presence and thereby, negotiating ongoing consent rather than assuming that their initial provisional consent held fast for the entirety of the research project (Flewitt 2005). In this respect, I found that by sharing the cartoons with the children I was, in effect, continually reminding them of my role in the classroom as a researcher, and this also resulted in the children being given regular opportunities to respond to the research, in positive or negative ways. As an example, when I shared a cartoon I had just drawn with one boy, he hid his face behind his hand and peered at me around the edge of his fingers - a clear indication that he was not happy for me to include that particular cartoon into my study, and it was withdrawn from the data bank.

The final ethical benefit of using cartoons is that of anonymity. Research participants of all ages have the right to confidentiality, yet researching with children, especially in schools, can make confidentiality difficult as many adults may be curious or concerned for the children (Graham et al. 2015). Photographs and videos are often used to document research with children and can be a powerful tool for capturing observations (Thomson 2010; Murray 2012; Chesworth 2016), however, according to my ethical agreement with the children and parents, these could be published as the children need to remain anonymous. Additionally, as a primary school teacher, I am personally uncomfortable taking any form of digital images of children for use outside the classroom, as this has been ingrained in me after years of following safeguarding procedures. Thus, cartoons enabled me to use a visual medium for representing the children that maintained their anonymity and yet was able to act as a valuable research medium.

\section{- Ethnographic honesty}

Ethnographic honesty requires the researcher acknowledges the intersubjective nature of the research process. Thus, they should recognise that it will require them to step out of the shadows, and to shine the light on their own positionality and experiences (Hammond and Wellington 2013). Whilst writing about oneself runs the risk of becoming either self-indulgent 
(Mukherji and Albon 2010) or simply futile (Johnson and Duberley 2003), (Lassiter 2005) argues that, on moral and ethical grounds, it is necessary to be open about the researcher's own experience whilst conducting the collaborative ethnography. In this respect, 'traditional' ethnographers have been criticised for using a purely 'etic' approach in which they were the sole interpreter of situations that were outside their own experience and for monopolising the dialogue by reporting their opinions as 'fact' (Dietz 2011). An alternative position that is commonly adopted is that of the "participant observer', yet (Tedlock 1991) explains the term in itself is an oxymoron as to be involved as a participant implies a relationship with the participants of the research, while observation implies a metaphorical distance between the researcher and the participants. To overcome this confusion of roles, Tedlock recommends the use of the term 'observation of participation' (Tedlock 1991, p.78), which places the ethnographer at the centre of the observation, and acknowledges that one's own experiences will shape one's interpretations of situations, settings and interactions.

A further complication to the researcher-participant relationship in my research project was that I am an adult and the participants were children- $\mathrm{a}$ relationship that is often fraught with cultural notions of power and control (Christensen 2004), compounded by the site of research being a school where there tends to be an established hierarchy of rights. In order to identify the role I would take on it was important to interrogate the often taken-forgranted social constructions 'adult' and 'child'(Heywood 2001). According to Geertz, the notion of a "chameleon fieldworker, perfectly self-tuned to his exotic surroundings", is a myth (Geertz 1983, p.56). I realised early it would not be possible to pass as a child and instead strove to perform the role of an adult 'friend' (Fine and Sandstrom 1988, p.17)- a role that meant I could remain an adult, yet I was different from the teachers and teaching assistants the children interacted with as I was not there to 'teach' them or to manage their behaviour. Over time, I realised that the children tended to talk to the teacher and teaching assistant about work or activities they were completing, however, when they spoke to me their conversations were much less formal. Thus, I endeavoured to highlight my involvement by including myself in the observations thereby ack the influence I had on the events.

\section{- Accessible writing}

In order to engage the participants in dialogue around the ethnographic texts being produced, the texts must be created in a clear and accessible format (Lassiter 2005). The participants in my research are children aged between four and five years old, and thus I could not share written observations with them, as they would not be able to read the texts. I considered reading the written observations aloud to the children, and then asking them to confirm its accuracy, however, the ability of the children in my study to [understand 
and] speak English varied from extremely fluent to absolute beginner. Therefore, conversing with the children in English would create a scenario in which the voices of those who spoke English well would be heard clearly, while those who were less fluent would potentially be ignored. I therefore needed to use a medium that was accessible to all participants, regardless of their age and ability to speak English.

One of Vygotsky's principle ideas was that in order for humans to convey experiences and thoughts to others a 'mediating system' is required (Vygotsky 1962). Whilst Vygotsky names speech as the primary mediating system through which communication is conducted, he also listed both art and drawings among other mediating tools (Brooks 2009). In this respect, drawings are a mode children use to 'talk' about their worlds, and children become 'fluent' in the language of drawing from a very young age (Anning and Ring 2001). This is exemplified by young children who incorporate drawings into their imaginative play as a meta-communicative tool for mediating collaborative activities (Wood and Hall 2011).

This use of visual aids as a communications medium has been taken up by teachers and practitioners who them when working with children who speak English as an additional language, often employing software such as 'Communicate: In Print' which creates low modality cartoon pictures of everyday objects. Such visual aids are available in every classroom at the school where the research was conducted, and children who do not speak English refer to these when trying to communicate, for example, that they need a pencil or the toilet. Cartoons, such as those produced by Social Stories ${ }^{\mathrm{TM}}$ are also widely used by practitioners to communicate with children with Autism Spectrum Disorders (The National Autistic Society 2004). While I do not claim that the needs of a child with autism are the same as, or even similar to, the needs of a child learning English, parallels can be drawn from the use of cartoons to improve social understanding while simultaneously helping parents and professionals to understand the perspectives of the student (Glaeser et al. 2003).

Thus, it has been established within both the literature and in practice that cartoons are accessible to young children, and that linguistic interaction is not necessary to interpret their meaning. This made cartoons an appropriate tool for sharing my observations with the children, and for facilitating dialogue around these observations.

\section{- Collaborative reading, writing and co-interpretation}

In order that ethnographic texts represent the participants' perspectives accurately, collaborative ethnography argues the participants should be involved in the reading, writing and co-interpretation of the texts. Thus, (Lassiter et al. 2004) discovered that they gained much deeper insights and 
understandings using this approach than if they had tried to analyse and interpret situations without consulting the participants. The rationale for this is the simple belief that: "if you would like to know what is going on it is best to ask the people involved" (Roffey et al. 1994, p.15). Similarly (Parker Webster and John 2010) draw on Vygotsky's notion of the 'Zone of Proximal Development' which is a space between people (in this case between the researcher and the participants) that symbolises the level of potential learning that is achievable through collaboration. Thus, while (Field 1999) acknowledges that collaboration at this level is not always achievable or possible, it should at least be attempted - and my research has been designed with this goal in mind.

The core task that I faced was to actively involve the children in the research by creating a stimulus to facilitate dialogue. (Lassiter 2005) outlines numerous strategies for facilitating collaborative reading, writing and cointerpretation however, these methods were inappropriate for my participants. The practical issues that arise when conducting research with young children are widely documented (Ryan and Campbell 2001); Brooker 2001; Fleer 2013), and in the case of this research it would, for example, be difficult to conduct a focus group with children aged four to five as they are often unwilling to sit for lengthy periods of time in order to answer questions. The practical challenges were compounded by the linguistic and cultural boundaries between the participants and myself as outlined above. However, cartoons provided a visual medium that can open up dialogue, thus allowing discussions to occur around their messages, meaning and interpretations (O’Brien et al. 2014).

\section{Collaboration through cartoons in practice}

The first phase of the analysis was aimed at interrogating the methodology and seeing in what ways the cartoons, in combination with interviews and observations, enabled the children to meaningfully participate in the research. This lead me to categories that will be discussed in an forthcoming publication, however for the purposes and scope of this article, I will select cartoons that enable me to demonstrate how the four pillars of collaborative ethnography (Lassiter 2005) are met by employing this research method. The second phase of the analysis is still ongoing and aims to answer the central research questions of the project by similarly adopting thematic analysis through a constructivist grounded theory approach (Charmaz 2014). The children selected their own pseudonyms, hence some interesting choices of names!

\section{Vignette 1: Ethics and Moral Responsibility}

This vignette shows three children of Pakistani origin however, Kaylo Ren and Caterpillar have lived in Sheffield since birth and Aman Ali moved here 
when he was a baby. Kaylo Ren, who is sitting on the carpet, making a fist with his thumb out horizontally to Aman Ali. Aman Ali notices the gesture and asks Caterpillar what it means. Caterpillar translates the gesture for Aman Ali, explaining it means "a little bit friend, a little bit not". This lead to Aman Ali going to sit next to Kaylo Ren to work out why he was only a 'little bit' friend, resulting in a reconsolidation of their friendship culminating in a full 'thumbs up'.

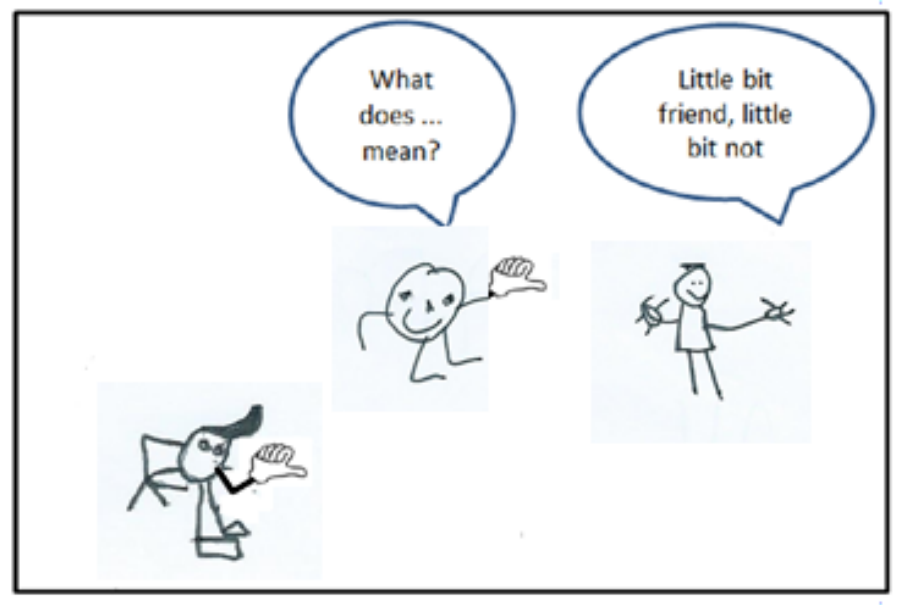

Vignette 1: ethics and moral responsibility

I have selected this vignette to demonstrate ethics and moral responsibility for several reasons. First, the vignette depicts a situation that could potentially appear trivial to an adult, as children often seem to fall out with each other and make friends again. Furthermore, the way Kaylo Ren communicated he was cross with Aman Ali could also be dismissed easily as a typical childish gesture- yet these are the very assumptions that imbue discourse around the child-adult dichotomy and need to be interrogated in order to take children seriously. I have argued that childhood is an important state in itself, and not just a stepping stone to adulthood (Qvortrup 2004) and that children are active social agents (Uprichard 2008) possessing the fundamental right to have an opinion (UNCRC 1989) and to have that opinion taken seriously (Brooker 2011). Thus, seemingly trivial interactions, such as the one depicted above, are actually significant events in the lives of children for whom friendships are incredibly important (Roffey et al. 1994; Rubin et al. 2008).

Secondly, the vignette shows how I have incorporated the children's selfportraits as 'avatars' in the cartoons. This came out of an event when I had drawn a cartoon and showed it to a child, pointing out which of the stick figures represented her. She took my pencil and drew herself saying "(referring to my drawing) that's not me, (referring to her drawing) that's me!". The children drawing their own self-portraits meant they felt an 
element of ownership over the cartoons and they appeared to be more vocal in their opinions of how the cartoons should look.

The next concern for ethics and moral responsibility that I will explore using this vignette is that of consent. There are two principle stages where the researcher must seek the participant's consent: initial, formal consent and ongoing consent. Initial, provisional consent was obtained from the parents and the children using a form with a cartoon to illustrate the purposes of the research. The cartoon provided another channel of communication and instigated dialogue around the project's aims. However, a key part of consent is the constant negotiation and renegotiation of ongoing consent (Graham et al. 2015). By showing the cartoons to the children, I was able to gauge how comfortable they were with me using that scene, and there were occasions where children reacted in ways that showed they did not consent, such as hiding their faces or shaking their heads.

The final reason this cartoon demonstrates how I have considered ethics and moral responsibility is to do with a basic human right that is key to any research project that claims to be ethical: anonymity. The children recognised their own avatars, but I did not share these with others, which enabled me to share the preliminary findings with interested adults, without divulging who was involved in the scene.

\section{Vignette 2: Ethnographic honesty}

The next vignette demonstrates how I upheld ethnographic honesty by acknowledging and reporting my influence on events. The vignette depicts Caterpillar, whose family speaks Urdu although his main language is English, playing in the role-play area with Aman Ali (who speaks Pashtu and Urdu), and some other friends who were not Urdu speakers. I heard Caterpillar call the other children 'buday' which means 'old people' in Urdu. I thought it was interesting that Caterpillar was speaking to the children who were not of Pakistani origin (and thereby did not speak Urdu), so I asked Caterpillar if the word 'buday' was his language. In honesty, I asked this because I was wondering if he was aware that the word 'buday' was not an English word and consequently not everyone would understand him. Aman Ali overheard my question and stated that his language was Spanish. I found this surprising, so I inquired further asking him to say something in Spanish and Aman Ali responded by singing a football chant for Yaya Toure. 


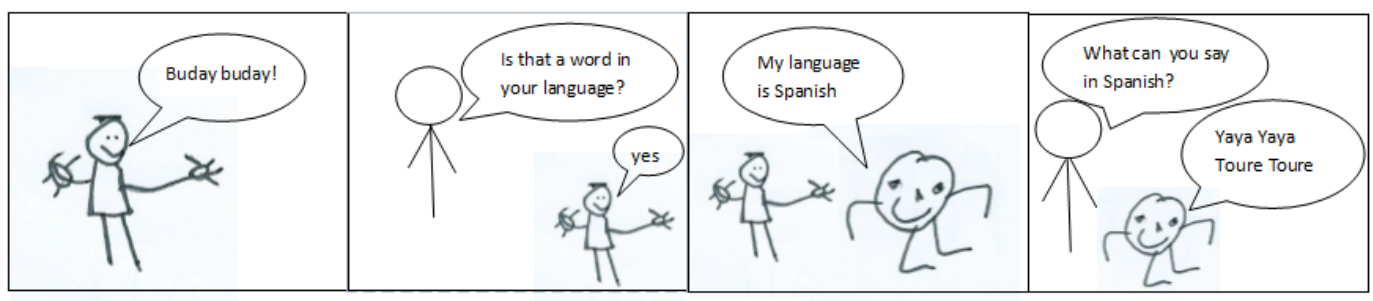

Vignette 2: ethnographic honesty

The scene was interesting with regards to my own research questions as it showed how Caterpillar has Urdu words in his repertoire that he used, despite his audience not all being able to understand Urdu. Through my probing, I was able to ascertain he has an awareness that Urdu is a different language to English. Furthermore, the interaction between myself and Caterpillar lead to a conversation with Aman Ali that raises some interesting questions regarding what it means to " 'know' a language" (Blommaert 2010, p.102) and whether knowing a football chant constitutes knowing a language. These discussions fall outside the scope of this current article; however, it does demonstrate the point: had I not interfered, this dialogue would not have arisen. I was very much a participant in the research at this point, while remaining observant (Tedlock 1991). Furthermore, I was not judgemental or critical of the children's understanding of languages and in this way I attempted to be an adult 'friend' (Fine and Sandstrom 1988, p.17).

\section{Vignette 3: Accessible Writing}

The following vignette shows how cartoons can assist communication with participants, especially those who do not speak the same language as the researcher. The two boys, Darth Vader and Igor are Roma and their families are originally from Slovakia. Both speak English at a very basic level. The class had taken a trip to the local Mosque in the morning and I was interested to know how much the boys had understood about the Mosque, given they are not Muslim, nor are they from a majority Muslim country. I asked them if they knew what 'Muslim' meant. Darth Vader began to flex his upper arms saying "my dad", Igor copied Darth Vader's actions. I realised they had understood 'muscles' instead of 'Muslim', so I asked if he knew what a 'Christian' was. In response both Darth Vader and Igor demonstrated their understanding by performing the posture Christians adopt when they pray. I knew from this action that they understood the term 'Christian. I asked if they knew why Christians prayed and Darth Vader said "Devloro", which I was later able to confirm with a Roma translator is the Romani word for God. I then referred to the sketch of the children performing a Christian praying and again asked if they knew what a 'Muslim' was. It appears that providing them with the context of prayer and God, and by looking at the visual images they were able to recall the meaning of the term 'Muslim' and they began to 
act out how Muslims pray. First Darth Vader declared, "You have to do like this!", and then Igor replies, "I know about that!" and copies Darth Vader (figure 4.1). When I was leaving the field, I gathered all the participants and showed them a short presentation of some of the cartoons we had created to show to all the children and to generate conversations around what had worked well and what could be improved upon in the future. Several Muslim children immediately commented, "They're praying!" and began to discuss different ways of praying and the ways their families pray.
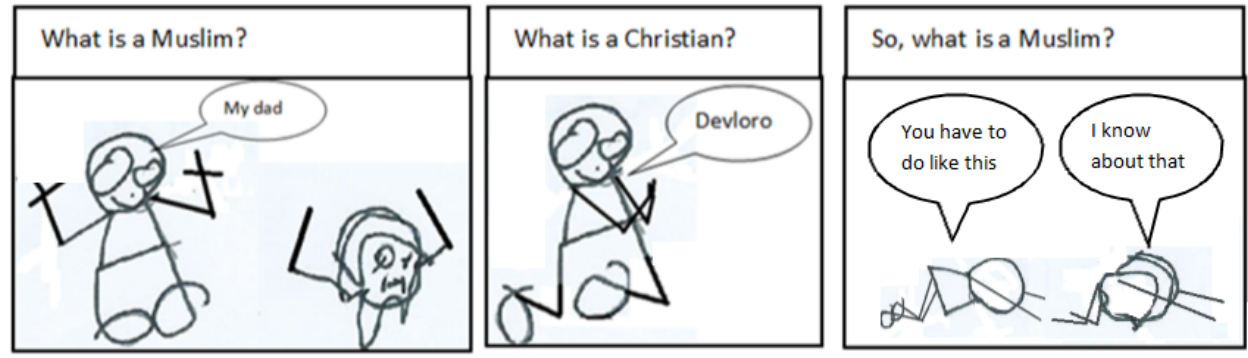

Vignette 3: Accessible Writing

The cartoon method was particularly appropriate in this instance because, as the children involved in the scene did not speak much English at the time, they relied heavily on gestures and performance to communicate their meaning (Gullberg 2006). I could have written a detailed description about their actions and poses, however using a visual image is better suiting to capture physical gestures. As they did not speak much English at the time, and I do not speak Romani, cartoons served as a medium for sharing my perception of the children's conception of religious identities without having to depend solely upon words. The cartoons created a space for dialogue, facilitating the evolution of the conversation from a basic misunderstanding ('muscles'), to a more sophisticated exchange involving multi-modal embodiment of the message they wanted to communicate. Furthermore, when I shared the vignette with the rest of the participants, their response was instantaneous as they recognised the gesture of praying and this generated further conversations around the different ways of praying in different religions.

\section{Vignette 4: Collaborative reading, writing and co-interpretation}

The final vignette demonstrates how the cartoons enabled me to open up spaces for dialogue with the children and to revisit events so they could help be interpret what was happening. In this scene Tomng, a Christian boy from the Tigray region of Ethiopia who spoke Tigrinya was talking to Asad, a Muslim, and Somali girl. Tomng does not have an avatar as he left the school shortly after my research began and I did not have the chance to ask him to draw one. Tomng announces that he found treasure in the sandpit. Asad tells him "say Wallah!" to which Tomng replies "um... Wallah?" in a very unsure 
tone of voice. Asad look very confused. It appeared Tomng was simply repeating the word 'Wallah' because he had been told to say it, but it seemed that he did not understand why he was saying it.

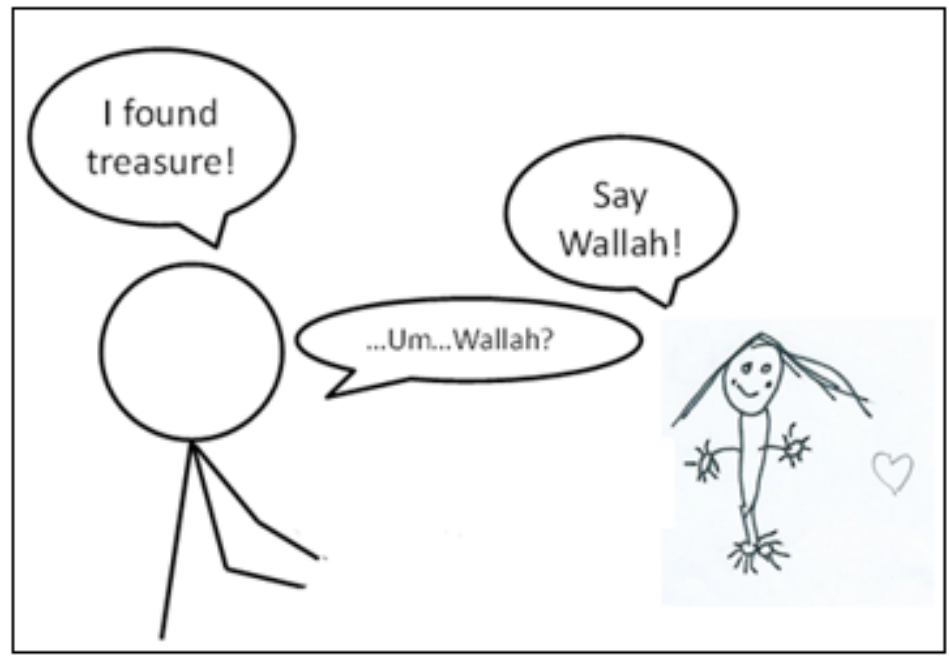

Vignette 4: Co-interpretation

I drew a sketch of the conversation, as I did not want to interrupt the flow of their dialogue. When they both returned to playing individually, I showed them the cartoon to help them recall the interaction. Tomng confirmed he did not know what Wallah meant. Asad suddenly understood why Tomng had repeated the word 'Wallah'. She explained that 'say Wallah' means 'tell the truth' and that her mum is always telling her sister to 'say Wallah' when she lies. This explanation helped Tomng and myself to understand what had occurred and how communication had broken down. 'Wallah' is actually a common phrase not only among Arabic speaking communities, but also among Muslim communities worldwide, thus as Tomng was neither an Arabic speaker, nor Muslim, he was unfamiliar with the word 'Wallah'. The children's co-interpretation of the situation was vital to my own understanding. While Lassiter (2005) recommends sharing written observations and co-interpretation through interviews, these methods would be inappropriate with such young children (Ryan and Campbell 2001); (Brooker 2001; Fleer 2013) thus the cartoons facilitated the goal cointerpretation through a different, more accessible medium.

\section{Conclusion}

In this article, I have shown how I used cartoons to assist the process of collaborative ethnography. I have argued for the need to address the power imbalance between the researcher and the participants who, in this case, are in a potentially vulnerable position due to their young age and their low level of English. Although the findings I present here are from one specific research 
project, there are multiple possibilities for applying a similar methodology to other research contexts as, I would argue, all social science research should attempt to engage with the participants and cartoons provide a powerful medium around which dialogue can develop.

I do not claim that I have unlocked the secret to eliminating the inherent asymmetry that exists between adult/child and researcher/participant. Nor do I believe I have created a tool that deems language and cultural barriers obsolete, as I recognise that ultimately, conversations around the cartoons relied on spoken language for clarification. I see cartoons as a vehicle that helps the researcher move towards balancing the power imbalance by creating a space where participants can engage with the research process through an accessible medium. 


\section{References}

Anning A and Ring K (2001) Early childhood narratives through drawing. Alkmaar. Available from: http://www.lboro.ac.uk/microsites/sota/tracey/journal/narr/ring.html (accessed 12 January 2016).

Blommaert J (2010) The sociolinguistics of globalization. Cambridge approaches to language contact, Cambridge, UK; New York: Cambridge University Press.

Bloome D and Green J (1997) Ethnography and Ethnographers of and in Education: A situated perspective. In: Flood J, Heath SB, Lapp D, et al. (eds), Handbook of research on teaching literacy through the communicative and visual arts, New York: London: Macmillan Library Reference USA; Prentice Hall International.

Braun V and Clarke V (2013) Successful qualitative research: a practical guide for beginners. Los Angeles: SAGE.

British Educational Research Association (2011) Ethical Guidelines for Educational Research. http://content.yudu.com/Library/A2xnp5/Bera/resources/index.htm? referrerUrl=ht tp://free.yudu.com/item/details/2023387/Bera. Available from: http://content.yudu.com/Library/A2xnp5/Bera/resources/index.htm?ref errerUrl=http://free.yudu.com/item/details/2023387/Bera (accessed 11 February 2017).

Brooker L (2001) Interviewing Children. In: MacNaughton G, Rolfe SA, and Siraj I (eds), Doing early childhood research: international perspectives on theory and practice, Buckingham [England] ; Phildelphia: Open University Press.

Brooker L (2011) Taking children seriously: An alternative agenda for research? Journal of Early Childhood Research 9(2): 137-149.

Brooks M (2009) What Vygotsky can teach us about young children drawing. International Art in Early Childhood Research Journal 1(1): 1-13.

Charmaz K (2014) Constructing grounded theory. London; Thousand Oaks, Calif: Sage Publications.

Chesworth L (2016) A funds of knowledge approach to examining play interests: listening to children's and parents' perspectives. International Journal of Early Years Education 24(3): 294-308.

Christensen PH (2004) Children's participation in ethnographic research: Issues of power and representation. Children $\mathcal{E}$ Society 18(2): 165-176. 
Dietz G (2011) Towards a doubly reflexive ethnography: A proposal from the anthropology of interculturality. Aibr-Revista De Antropologia Iberoamericana 6(1): 3-26.

Field LW (1999) Complicities and Collaborations: Anthropologists and the “Unacknowledged Tribes" of California. Current Anthropology 40(2): 193-210.

Fine GA and Sandstrom KL (1988) Knowing children: participant observation with minors. Qualitative research methods, Newbury Park, Calif: Sage Publications.

Fleer M (2013) Beyond Developmental Geology: A cultural-historical theorisation of digital visual technologies for studying young children's development. In: Visual methodologies and digital tools for researching with young children: transforming visuality, New York: Springer, pp. 15-32.

Flewitt R (2005) Conducting research with young children: some ethical considerations. Early Child Development and Care 175(6): 553-565.

Gallagher M, Haywood SL, Jones MW, et al. (2010) Negotiating Informed Consent with Children in School-Based Research: A Critical Review: Informed Consent: A Critical Review. Children \& Society 24(6): 471-482.

Geertz C (1983) Local knowledge: further essays in interpretive anthropology. New York: Basic Books.

Glaeser B, Pierson M and Fritschmann N (2003) Comic Strip Conversations: A Positive Behavioural Strategy. Teaching Exceptional Children 36(2): 14.

Graham A, Powell MA and Taylor N (2015) Ethical Research Involving Children: Encouraging Reflexive Engagement in Research with Children and Young People. Children \& Society 29: 331-343.

Gullberg M (2006) Some reasons for studying gesture and second language acquisition (Hommage à Adam Kendon). IRAL - International Review of Applied Linguistics in Language Teaching 44(2). Available from: http:// www.degruyter.com/view/j/iral.2006.44.issue2/iral.2006.004/iral.2006.004.xml (accessed 9 August 2016).

Hammond M and Wellington JJ (2013) Research methods: the key concepts. Routledge key guides, London ; New York: Routledge.

Heywood C (2001) A history of childhood: children and childhood in the West from medieval to modern times. Cambridge, UK; Malden, Mass: Polity Press.

Johnson P and Duberley J (2003) Reflexivity in Management Research*. Journal of Management Studies 40(5): 1279-1303. 
Kirk S (2007) Methodological and ethical issues in conducting qualitative research with children and young people: A literature review. International Journal of Nursing Studies 44: 1250-1260.

Lahman M (2008) Always Othered: Ethical research with children. Journal of Early Childhood Research 6(3): 281-300.

Lassiter LE (2005) The Chicago guide to collaborative ethnography. Chicago guides to writing, editing, and publishing, Chicago: University of Chicago Press.

Lassiter LE (2012) 'To Fill in the Missing Piece of the Middletown Puzzle': Lessons from Re-Studying Middletown. The Sociological Review 60(3): 421-437.

Lassiter LE, Goodall H, Campbell E, et al. (2004) The Other Side of Middletown: Exploring Muncie's African American Population. Walnut Creek CA: Alta Mira.

Malinowski B (1922) Argonauts of the Western Pacific: an account of native enterprise and adventure in the Archipelagoes of Melanesian New Guinea; [Robert Mond expedition to New Guinea 1914 - 1918]. Reprinted. London: Routledge.

Mukherji P and Albon D (2010) Research methods in early childhood: an introductory guide. Los Angeles; London: SAGE.

Murray J (2012) Young children's explorations: young children's research? Early Child Development and Care 182(9): 1209-1225.

O'Brien V, Dhuffar M and Griffiths MD (2014) Collaborative Visual Ethnography: Practical Issues in Cross-Cultural Research. 1 Oliver's Yard, 55 City Road, London EC1Y 1SP United Kingdom: SAGE Publications, Ltd. Available from: http://methods.sagepub.com/case/collaborative-visualethnography-practical-issues-cross-cultural-research (accessed 5 February 2017).

Parker Webster J and John TA (2010) Preserving a space for cross-cultural collaborations: an account of insider/outsider issues. Ethnography and Education 5(2): 175-191.

Qvortrup J (2004) Editorial: The waiting child. Childhood 11(3): 267-273.

Roffey S, Tarrant T and Majors K (1994) Young friends: schools and friendship. London; New York, NY: Cassell.

Rubin K, Fredstrom B and Bowker J (2008) Future Directions in ... Friendship in Childhood and Early Adolescence. Social Development 17(4): 1085-1096. 
Ryan S and Campbell S (2001) Doing research for the first time. In: MacNaughton G, Rolfe SA, and Siraj I (eds), Doing early childhood research: international perspectives on theory and practice, Buckingham [England]; Phildelphia: Open University Press, pp. 56-63.

Tangen R (2008) Listening to children's voices in educational research: some theoretical and methodological problems. European Journal of Special Needs Education 23(2): 157-166.

Tedlock B (1991) From Participant Observation to the Observation of Participation: The Emergence of Narrative Ethnography. Journal of Anthropological Research 47(1): 69-94.

The National Autistic Society (2004) Social Stories TM and Comic Strip Conversations: Information Sheet. Available from: http://nasmorayandnairn.org/a/wp-content/uploads/2014/03/Socialstories.pdf (accessed 16 January 2016).

Thomson P (2010) Doing visual research with children and young people. London; New York: Routledge.

UNCRC (1989) The United Nations Convention on the Rights of a Child.

UNICEF (1989) Fact Sheet: A summary of the rights under the Convention on the Rights of a Child. Available from: http://www.unicef.org/crc/files/Rights_overview.pdf (accessed 1 June 2015).

Uprichard E (2008) Children as 'Being and Becomings': Children, Childhood and Temporality. Children and Society 22(4): 303-313.

Vygotsky LS (1962) Thought and Language. Cambridge: Massachusetts: MIT Press.

Wood E and Hall E (2011) Drawings as spaces for intellectual play. International Journal of Early Years Education 19(3-4): 267-281. 